\title{
Diferenciação de tipos de Mycoplasma mycoides na etiopatogenia da micoplasmose caprina
}

\section{Differentiation of Mycoplasma mycoides types on the etiopathogeny of goat mycoplasmosis}

\author{
Valquíria Pinto Barbosa, ${ }^{\star}$ Elmiro Rosendo do Nascimento, ${ }^{\star \star}$ Maria das Graças Miranda Danelli, ${ }^{\star}$ Maria da Graça Fichel do \\ Nascimento, ${ }^{\star \star \star}$ Marcos Antônio José dos Santos, ${ }^{\star \star \star *}$ Gilberto Brasil Lignon, ${ }^{\star \star \star}$ Vinícius Resende Ribeiro ${ }^{\star \star \star \star}$
}

\begin{abstract}
Resumo
Dentre as várias espécies e subespécies de micoplasma, isoladas de caprinos, Mycoplasma mycoides subesp. mycoides e M. mycoides subesp. capri, são considerados importantes patógenos, por produzirem doenças com diversas manifestações clínicas (infecções sistêmicas, pneumonia, artrite, agalaxia etc.). O propósito desse estudo foi pesquisar a presença dessas subespécies em caprinos com diagnóstico de micoplasmose, oriundos de uma propriedade localizada em Nova Friburgo, município do estado do Rio de Janeiro. Na coleta de espécimes para o diagnóstico, usou-se o método de lavagem do conduto auditivo externo de 20 animais, utilizando-se o meio líquido de Hayflick. Após a obtenção dos lavados de ouvido, as amostras foram cultivadas segundo os procedimentos padrões. Os cultivos em placa foram examinados em microscópio estereoscópico, visando a observação de colônias típicas de micoplasma. Essas colônias foram coradas pelo método de Dienes, submetidas aos testes de sensibilidade à Digitonina e Imunoperoxidase Indireta (IPI), para posterior identificação. Todos os caprinos examinados apresentaram cultivo positivo para Mycoplasma spp., i.é, 100\% (20/20) e desses, 80\% (16/20) foram positivos para $M$. mycoides. Das amostras positivas para $M$. mycoides, $70 \%(14 / 16) \circ$ foram para $M$. mycoides subesp. mycoides tipo Colônia Grande ("Large Colony-LC"), 45\% (9/16) para M. mycoides subesp. mycoides tipo Colônia Pequena ("Small Colony-SC") e 70\% (14/16) para M. mycoides subesp. capri, onde 12 dos 16 caprinos examinados portavam mais de uma subespécie e/ou tipo no conduto auditivo. No presente estudo foram encontrados micoplasmas com características de ambas as subespécies e tipos ( $L C$ e SC), no conduto auditivo externo de caprinos, sugerindo a necessidade de estudos adicionais para elucidação da etiopatogenia das micoplasmoses caprinas.
\end{abstract}

Palavras-chave: caprinos; Mycoplasma mycoides; micoplasmose.

\begin{abstract}
Among the various species and subspecies of mycoplasma isolated from goats, Mycoplasma mycoides subsp. mycoides and Mycoplasma mycoides subsp. capri have been considered important pathogens, due to disease production wit different clinical manifestations (systemic infection, pneumonia, arthritis, agalactia, etc). The objective of this study was to search for the presence of these subspecies in goats with diagnosis of mycoplasmosis, from one farm located in Nova Friburgo Municipality Rio de Janeiro State, Brazil. For the diagnosis, the specimens were collected by using the method of external ear canal flushing with Hayflick broth medium. After collecting the flushed material, the samples were cultured according to the standard procedures. Cultures on agar plates were examined under stereomicroscope, in order to observe the typical growth of mycoplasma colonies. These colonies were then stainned by the Dienes's method, submitted to Digitonin Sensitivity and to the Indirect Immunoperoxidase Tests, for further identification. All studied goats were culture positive for Mycoplasma spp., i. e, 100\% (20/ 20) positive, and from these, $80 \%(16 / 20)$ were positive for $M$. mycoides. From the $M$. mycoides positive samples, $70 \%$ (14/16) were M. mycoides subsp. Mycoides Large Colony (LC) type, 45\% (9/16) were M. mycoides subsp. mycoides Small Colony (SC) type, and $70 \%(14 / 16)$ were $M$. mycoides subsp. capri. Out of those 16 goats $M$. mycoides positive, 12 had more than one mycoplasma subspecies and/or type in the ear canal. In the present study, it was found mycoplasma with characteristics of both M. mycoides subspecies of both LC and SC types, in the external ear canal of a single goat, suggesting the need of additional studies for the elucidation of the etiopathogeny of goat mycoplasmosis.
\end{abstract}

Keywords: goats; Mycoplasma mycoides; Mycoplasmosis.

\footnotetext{
* Instituto de Veterinária/Universidade Federal Rural do Rio de Janeiro (UFRRJ). Km 47 da Antiga Rodovia Rio-São Paulo, $23890-000$ Seropédica, RJ. **Faculdade de Veterinária/Universidade Federal Fluminense (UFF). Rua Vital Brazil Filho, 64, 24230-340, Niterói, RJ.

***Projeto Sanidade Animal (CNPAB-Embrapa/UFRRJ),

$\star \star \star \star$ Instituto de Biologia/UFRRJ.
} 


\section{Introdução}

Dentre as enfermidades que afetam os caprinos, as micoplasmoses ressaltam-se em importância, sendo responsáveis por perdas econômicas significativas na caprinocultura de todo mundo (Cottew, 1979 ; DaMassa et al., 1992). No Brasil, mesmo sabendo-se da gravidade das micoplasmoses caprinas desde o início da década de 40 (Penha, D' Apice, 1942), os trabalhos sobre o assunto têm sido numericamente inexpressivos diante do impacto econômico que as infecções micoplásmicas representam para a Caprinocultura Nacional (Penha, D’Apice, 1942 ; Rodwell, Rodwell, 1978 ; Nascimento, Nascimento, 1982 ; Nascimento, Nascimento, 1984a ; Nascimento, Nascimento, 1984b ; Gomes et al., 1994 ; Nascimento et al., 1986 ; Nascimento et al., 1990 ; Ribeiro, 1994 ; Ribeiro et al., 1997).

Existem várias espécies patogênicas de micoplasma que acometem os caprinos, tais como o $M$. agalactiae, $M$. capricolum subesp. capricolum, $M$. mycoides subesp. capri, $M$. mycoides subesp. mycoides tipo ("Large Colony - LC"), M. conjuctivae, $M$. ovipneumonie, $M$. capricolum subesp. capripneumonia (DaMassa, 1996 ; DaMassa et al., 1992) etc. De todas essas espécies, o M. mycoides vem atraindo particular interesse, tendo sido isolado de casos esporádicos de peritonite fibrinosa (Littlejohns, Cottew, 1977), infecção ocular (Jonas, Barber, 1969), pneumonia caprina (Nascimento et al., 1986), poliartrite (Rosendal et al., 1979) e outras afecções. Devido à proximidade genética, é comum obter reações cruzadas entre as subespécies mycoides (Rodwell, Rodwell, 1978).

O presente trabalho objetivou o diagnóstico de micoplasmose caprina em nível de subespécies e tipos com ênfase para $M$. mycoides nos lavados do conduto auditivo de caprinos de um rebanho leiteiro.

\section{Material e métodos}

Animais e procedência: Foram utilizados 20 caprinos, sendo 18 fêmeas e dois machos, com idades entre seis meses a cinco anos. Todos mestiços, com características leiteiras e provenientes de um único criatório em regime de confinamento, localizado no município de Nova Friburgo, região serrana do estado do Rio de Janeiro.

Coleta de espécimes: Em visita à propriedade e, após a contenção dos animais, as coletas de espécimes para o diagnóstico foram efetuadas individualmente, através da lavagem do conduto auditivo (Ribeiro et al., 1997), para a obtenção de micoplasmas e ácaros. As lavagens foram feitas com o próprio meio líquido para cultivo de micoplasma - Hayflick modificado (Freudt, 1983), usando-se um aparelho de lavagem, esterilizado, por animal.

Cultivo e visualisação de micoplasmas: As alíquotas dos lavados de conduto auditivo foram semeadas em meio sólido de Hayflick modificado, para o isolamento de micoplasma. As placas foram incubadas a $37^{\circ} \mathrm{C}$, em microaerofilia, pelo uso de jarra com vela acesa e examinadas no período de 48 a 72 horas, em microscópio estereoscópico. Após a verificação do crescimento, blocos de ágar contendo colônias típicas foram transferidos para tubos com tampa de rosca, contendo meio líquido de Hayflick modificado e incubados a $37^{\circ} \mathrm{C}$. Os tubos foram examinados no prazo de 24-48 horas, para a observação da mudança de cor, devido à alteração do pH do meio. Após a verificação da mudança de cor, os cultivos em meio líquido foram misturados a $1: 3 \mathrm{em}$ glicerol e estocados a $-20^{\circ} \mathrm{C}$ (Nascimento, Nascimento, 1984b).

Classificação dos micoplasmas isolados: As colônias típicas de micoplasma, i. é, Mollicutes, crescidas em meio sólido, foram diferenciadas de "formas L" de bactéria pelo método de coloração de Dienes (1945). A observação das colônias de micoplasma, cujos centros coram-se intensamente de azul, circundados por um halo de azul mais claro, foi feita em microscópio estereoscópico com ampliação de 40 a 100x. A diferenciação entre micoplasma, que é dependente de colesterol e acoleplasma, que não necessita desse esterol, foi realizada pelo teste de sensibilidade à Digitonina, conforme técnica anteriormente padronizada (Tully, 1983). A sorotipagem foi realizada pelo teste de Imunoperoxidase Indireta, e empregou antissoros específicos, produzidos em coelho, para Mycoplasma mycoides subesp. mycoides Tipo SC, Mycoplasma mycoides subesp. mycoides Tipo LC e Mycoplasma mycoides subesp. capri, conforme descrito anteriormente (Imada et al., 1987). Devido à existência de reações cruzadas observadas entre as subespécies e tipos de $M$. mycoides (Rodwell, Rodwell, 1978), houve necessidade de se padronizar os antissoros utilizados, homólogos e heterólogos, para serem empregados na tipificação das amostras de campo, no presente estudo. O teste de Imunoperoxidase Indireta foi feito utilizando a diluição do soro que não proporcionou reatividade cruzada entre os soros heterólogos e, como conseqüência, eliminando os resultados falso-positivos.

\section{Resultados}

De todos os animais estudados, obteve-se isolamento de colônias típicas de micoplasmas em forma de "ovo-frito", após um período de incubação de 24 horas. Todas as amostras obtidas foram confirmadas como Mollicutes, através do emprego do corante de Dienes e pertencentes, em 100\%, ao gênero Mycoplasma por terem sido sensíveis à Digitonina. As amostras apresentaram halos de inibição em volta do disco de digitonina, que variaram de 12 a $21 \mathrm{~mm}$ de diâmetro.

A caracterização de $M$. mycoides em subespécies mycoides, tipos SC e LC, e capri, feita através da técnica de Imunoperoxidase Indireta em placa, revelou que, dos 20 caprinos, examinados, $80 \%(16 / 20)$ foram positivos para $M$. mycoides. Desses caprinos M. mycoides positivos, $56 \%$ (9/ 16) tinham $M$. mycoides subesp. mycoides (SC e LC) e $M$. mycoides subesp. capri; $18 \%$ (3/16), M. mycoides subesp. mycoides (LC) e $M$. mycoides subesp. capri; $13 \%(2 / 16)$ tinham apenas $M$. mycoides subesp. mycoides (LC) enquanto $13 \%(2 / 16)$ tinham somente $M$. mycoides subesp. capri. Desta forma, das cepas de $M$. mycoides, obtidas, $70 \%(14 / 16)$ foram M. mycoides subesp. mycoides (LC), 45\% (9/16), $M$. mycoides subesp. mycoides (SC) e $70 \%$ (14/16) M. mycoides subesp. capri.

\section{Discussão e conclusão}

No presente trabalho, foi diagnosticado micoplasma patogênico no conduto auditivo externo de caprinos aparentemente sadios, estando em conformidade com relatos prévios (Cottew, Yeats, 1982), onde foram observados caprinos clinicamente sadios abrigando várias espécies de micoplasmas no conduto auditivo externo, incluindo espécies patogênicas. 
O isolamento de cepas tipificadas como Mycoplasma mycoides subesp. mycoides SC não confirma o agente da Pleuropneumonia Contagiosa Bovina (PPCB), uma vez que os micoplasmas desse grupo são genética e fenotipicamente difíceis de serem distinguidos, além de existir também o tipo colônia pequena de origem caprina (Nascimento et al., 1986).

O isolamento do agente é a mais forte evidência da infecção, embora os caprinos estudados não apresentassem sinais clínicos aparentes de micoplasmose, fato este também observado em trabalhos prévios (Cottew, Yeats, 1982). Entretanto, esta condição de latência pode levar a uma infecção clínica, manifestada por um quadro agudo com a morte súbita de animais, conforme preconizado (DaMassa et al., 1992). Uma conseqüência evidente da presença de micoplasmas patogênicos no conduto auditivo de caprinos clinicamente sadios é a transmissão desses agentes para outros rebanhos, carreados por animais portadores, conforme já observado por outros pesquisadores (Cottew, Yeats, 1982). Devido à detecção de Mycoplasma spp. em 20 espécimes examinados, onde somente 16 deles foram tipados como Mycoplasma mycoides, pôde-se confirmar a existência de mais de uma espécie coabitando o conduto auditivo caprino, em concordância com os relatos de outros autores (Cottew, Yeats, 1982 ; DaMassa, 1983 ; DaMassa, Brokks, 1991).
No presente trabalho, foram isolados $M$. mycoides subesp. Mycoides (SC e LC) e M. mycoides subesp. capri, i.e., duas subespécies patogênicas, provenientes do conduto auditivo de um só caprino, fenômeno já observado no Rio de Janeiro, mas por ocasião de um surto (Nascimento et al., 1986). Em outro relatado nos Estadós Unidos da América, houve o isolamento de $M$. mycoides subesp. mycoides LC e M. mycoides subesp. capri, além de $M$. capricolum subesp. capricolum, $M$. putrefaciens, $M$. agalactiae, $M$. auris, $M$. cottewii e $M$. yeatsi, do conduto auditivo de um só caprino clinicamente sadio (DaMassa, Brooks, 1991). Houve, ainda, um alto índice de isolamento de Mycoplasma mycoides nas amostras estudadas, o que pode significar uma alta ocorrência desse agente na Região Serrana, apesar de apenas uma propriedade ter sido estudada. Estes achados estão em conformidade com um levantamento na Mesorregião do Estado do Rio de Janeiro, onde foi notificado o isolamento de $M$. mycoides em todas as propriedades estudadas (Ribeiro, 1994).

O trabalho deixou claro a convivência de uma ou mais subespécies de $M$. mycoides em um mesmo caprino, além de outras espécies, não classificadas, demonstrando a necessidade de novos estudos para a elucidação desse nicho como habitat dos micoplasmas e subseqüente fonte de infecção para outros rebanhos caprinos.

\section{Agradecimentos}

Aos funcionários Luís Carlos Chaves e Marildo Azevedo, do CNPAB-PSA, Embrapa/UFRRJ, pela inestimável ajuda no preparo da vidraria e elaboração de reagentes e meios de cultura utilizados no presente trabalho.

Ao CNPq, pelo auxílio à realização deste trabalho.

\section{Referências bibliográficas}

COTTEW, G.S. Caprine-ovine Mycoplasmas. In: TULLY, J.G., WHITCOMB, R.F. (ed.). The Mycoplasmas. Human and Animal Mycoplasmas, Academic Press., 1979. p.103-132.

YEATS, F.R. Mycoplasmas and mites in the ears of clinically normal goats. Aust. Vet. J. v. 59, p. $77-81,1982$.

DaMASSA, A.J. Prevalence of mycoplasmas and mites in the external auditory meatus of goats. Calif. Vet., v. 37, p. 10-13,17, 1983.

Mycoplasma infections of goats and sheep. In: TULLY, J.G.; RAZIN, S. (ed.). Molecular and Diagnostic Procedures in Mycoplasmology. Academic Press., 1996. p. 265-273.

, BROOKS, D.L. The extemal ear canal of goats and other animals as a mycoplasma habitat. Small Ruminant Res., v. 4, p. 85-93, 1991.

, WAKENELL, P.S., BROOKS, D.L. Review Article. Mycoplasmas of goats and sheep. J. Vet. Diagn. Invest., v. 4, p. 101-113, 1992.

DIENES, L. Morphology and nature of the pleuropnemonia group of organism. Journal of Bacteriology., v. 50, p. 441-458, 1945.

FREUDT, E.A. Culture media for classic mycoplasmas . In: RAZIN, J.S., TULLY, J.G. (ed.). Methods in Mycoplasmology: Mycoplasma characterization. Academic Press., 1983. p. 130.

GOMES, M.J.P., FEITOSA, M.H., KHRAL, M., FERNANDES, R.E., NASClMENTO, E.R., PORTUGAL, M.A.S.L. Micoplasmose caprina: pneumonia . Primeiro relato no Brasil de Mycoplasma arginini. Hig. Alim., v. 8, p. 18-20, 1994.
IMADA, Y., UCHIDA, I., HASHIMOTO, K. Rapid identification of mycoplasmas by indirect immunoperoxidase test using small square filter paper. J. of Clin. Microbiol., v. 25, p. 17-21, 1987.

JONAS, A.M., BARBER, T.L. Mycoplasma mycoides var. capri isolated from goat. J. Infect. Dis., v. 119, p. 126-131, 1969.

LITTLEJOHNS, I.R., COTTEW, G.S. The isolation and identification of Mycoplasma mycoidessubsp. capri from goats in Australia. Aust. Vet. J., v. 53, p. 297-298, 1977.

NASCIMENTO, E.R., NASCIMENTO, M.G.F., FREUNDT, E.A., ANDERSEN, $\mathrm{H}$. Isolation of Mycoplasma mycoidesfrom outbreaks of caprine mycoplasmosis in Brazil. Br. Vet. J., v. 142, p. 246-257, 1986.

, YAMAMOTO, R. Pathogenicity study in goats of Mycoplasma mycoides strain 108/A2 isolated in Brazil. In: Proc. VIII Intern. Cong. Intern. Organiz. Mycoplasmol. (IOM) Instanbul, Turquia., 1990. p. 501-502.

NASCIMENTO, M.G.F., NASCIMENTO, E.R. Isolamento de Mycoplasma argininiem caprinos. CONGRESSO BRASILEIRO DE MEDICINA VETERINÁRIA, 18., 1982, Camboriú, Anais... p. 74.

Isolamento de Mycoplasma ovipneumoniae de caprinos com pneumonia. CONGRESSO BRASILEIRODEMEDICINA VETERINÁRIA, 1984a, Belém, Anais... p.304

. Estocagem e sobrevivência de várias espécies de micoplasmas a $-20^{\circ} \mathrm{C}$. CONGRESSO BRASILEIRO DE MEDICINA VETERINÁRIA, 19., 1984b, Belém, Anais... p.307. 
PENHA, A. M., D' APICE, M. Agalaxia contagiosa das cabras em São Paulo. Arq. Inst. Biol., v. 13, p. 299-301, 1942.

RIBEIRO, V.R. Alguns aspectos relacionados com a associação entre micoplasmas e ácaros da espécie Raillietia caprae, parasitos de conduto auditivo externo de caprinos. 1994. 55 f. Tese (Doutorado) - Instituto de Biologia - Universidade Federal Rural do Rio de Janeiro.

, NASCIMENTO, E.R., FACCINI, J.L.H., NASCIMENTO, M.G.F., LIGNON, G.B. An improved method for the recovery of mycoplasmas from the external ear canal of goats. J. Vet Diag. Invest., v. 9, p. 156-158, 1997.
RODWELL, A.W. \& RODWELL, E.S. Relationship between strains of Mycoplasma mycoides subsp. mycoidesand capristudied by twodimensional gel electrophoresis of cell proteins. J. Gen. Microbiol, v. 109, p. 259-263, 1978.

ROSENDAL, S., ERNO, H., WYAND, D.S. Mycoplasma mycoides subspécies mycoides as a cause of polyarthritis in goats. J. Am. Vet. Med Assoc., v. 175, p. 378-380, 1979.

TULLY, J. G. Test for digitonin sensitivity and esterol requirement. In: RAZIN S., TULLY, J. G. (ed.) Methods in Mycoplasmology. Mycoplasma Characacterization. Academic Press, 1983. p. 355-362. 